\title{
The Analysis of the 2008 US Financial Crisis: An Intervention Approach
}

\author{
Katleho Daniel Makatjane ${ }^{1}$, Edward Kagiso Molefe ${ }^{2}$, Roscoe Bertrum van Wyk ${ }^{3}$ \\ ${ }^{1}$ Basetsana Consultants, Mahikeng, South Africa \\ ${ }^{2}$ North West Department of Finance, Mahikeng, South Africa \\ ${ }^{3}$ University of Stellenbosch Business School, Stellenbosch University, Cape Town, South Africa \\ katleho.makatjane@outlook.com, edwardmolefe22@gmail.com, roscoevanwyk@gmail.com
}

\begin{abstract}
The current study investigates the impact of the 2008 US financial crises on the real exchange rate in South Africa. The data used in this empirical analysis covers the period from January 2000 to June 2017. The seasonal autoregressive integrated moving average (SARIMA) intervention charter was used to carry out the analysis. Results revealed that the financial crises period in South Africa occurred in March 2008 and significantly affected the exchange rate. Hence, the impact pattern was abrupt. Using the SARIMA model as a benchmark, four error metrics; to be precise mean absolute error (MAE), mean absolute percentage error (MAPE), mean error (ME) and mean percentage error (MPE) was used to assess the performance of the intervention model and SARIMA model. The results of the SARIMA intervention model produced better forecasts as compared to that one of SARIMA model. Furthermore, the results of this empirical analysis provided practical information for the monetary policy committee of SA to make informed policy decisions related to exchange rate movements and we further give sound relevance in using the intervention model to model interrupted time series such as exchange rates.
\end{abstract}

Keywords: Real exchange rate, SARIMA intervention, South Africa, Financial crisis

\section{Introduction}

The 2007-2008 worldwide financial crisis was an astonishing and multifaceted process. According to Orlowski (2008), the financial crises came as a result of surplus liquidity of which the Federal Reserve Chairman Ben Bernanke had excess savings that were used in the worldwide financial markets as well as on mortgage markets in the United States (US). Moreover, insufficient assets and liability and risk management practices of financial organizations resulted in the advancement of the 2007-2008 financial crisis. The widespread density of this crisis had spillovers that affected many areas in the economy such as financial markets, commodity markets and real economy (Orlowski, 2008). Chung, Ip and Chan (2009) emphasized that during 2007-2008, the national government altered endeavours not to significantly disturb mortgage markets. For that reason, the crisis had gone through five distinct stages. As stated by Orlowski (2008), the first stage occurred when the US fall into the housing bubble, which was bloated by significant mortgage lending. The second stage identified other types of assets that were covered by this crisis. This stage not only impacted mortgage companies but also investment banks together with other banks worldwide. The third stage represented a colossal addendum of the liabilities from exposed banks which prompted the international liquidity crisis. This triggered anxiety about possible credit contagion as of the same risk on the universal scale. The fourth stage was the disintegrating of investment product structures which eliminates the comprehensive liquidity provisions into an article of trade, causing the bubble effect in this area. Lastly, a zenith was reached in September 2008 with massive shifting of funds into risk-free securities, as Lehman Brothers filed for bankruptcy protection and US investment banking system faced its ultimate demise (Chung, Farrish and Wang, 2009).

The empirical study conducted by Naudé (2009) exposed that the 2007-2008 financial crisis was of a vast magnitude and significantly affected worldwide economies. Most economies started to recognize the effect of this crisis in March 2008. Therefore, the rationale of this study was to evaluate whether the 2007-2008 financial crisis had a transitory or long-term effect on the South African economy utilizing the SARIMA intervention procedure. The study utilises the intervention model to assess the patterns and duration of the financial crisis on SA real exchange rate of South Africa. Furthermore, to appraise whether the crisis had a transitory or permanent effect on the economy of South Africa. The empirical analysis utilized in this study is divided into three stages. Firstly, the SARIMA model was used as a benchmark to describe the SA exchange rate. Furthermore, an intervention analysis is performed to appraise the effects of the 2008 financial crisis and further gives a formal test to assess the effect. This will assist the Monetary Policy Committee (MPC) of SA to understand systematically the linear co-movement of the exchange rate in SA. Lastly, a comparative analysis 
was directed to survey whether the intervention analysis successfully represents the waves of 2008 financial crisis contrasted with SARIMA. This study will add to the existing literature since there are limited studies that fully utilize the intervention models in South African context.

\section{Review of Supporting Literature}

The structural breaks in the data can be examined exogenously by assessing their impacts with an ARIMA model that is developed on the bases of a time series. The difference between the actual data and the data without the bearing is known as the degree of the power of an exogenous event. According to Zheng (2014), the amount of data fluctuations that is more than or less than expected is based on the data trends before the intervention event. Utilisation of the intervention in analysis can determine the statistical influence of an exogenous intervention on a given time series and measure the magnitude of the impact if any (Zheng et al., 2013). Many researchers have used the intervention model to analyse a variety of time series that are prone to structural breaks. This includes among others Coshall (2003), who examined the impact of the September 11 terrorist attacks on international travel flows. Further, Lai and Lu (2005) quantified a significant decline in the demand of the air transport passengers in the US after the terrorists attack on September 11. Eisendrath et al. (2008) measured the waves of the September 11 terrorist attack on Las Vegas strip gaming volume. Min et al. (2011), used an intervention model to analyze the consequence of Severe Acute Respiratory Syndrome (SARS) on Japanese tourism demand for Taiwan. Zheng et al. (2013) examined the impact of the 2007 recession on US restaurant stocks by employing an intervention model.

SARIMA model with the intervention was a used by Ebhuoma, Gebreslasie and Magubane (2017) to model the end product of the re-introduction of dichlorodiphenyltrichloroethane (DDT) on confirmed monthly malaria cases. Results revealed that both sudden and a perpetual monthly decline in malaria. The cause of this decline was the aftermath of implementing the intervention policy on malaria disease. According to Ebhuoma et al. (2017), there has been a long period observation of low malaria which advocates that the continual treatment of DDT did not result in insect repellent as predicted. Therefore, the feasibility of reducing malaria transmission to zero in KwaZulu Natal (KZN) requires other reliable and complementary intervention resources to optimize the existing ones Mayosi et al. (2012). To arrange for the evidence that is related to the waves of inaugural of the demand changes of the new railway line in Seoul, Park, Eom, Heo and Song (2016) used a public transport smart card data to apply the intervention model to assess the demand travel patterns on the changes at the transfer station. Their results proved that the new line opening has evocative effects on passenger demand and furthermore, substantial changes were latent in all stations. This implies that the trends have been changed structurally and the changes may last for a long time. For more readings see Xie, Sun, and Chen (2010), Zhang et al. (2011), Ye, Szeto and Wong. (2012) and Lippi, Bertini and Frasconi (2013).

Moreover, Etuk and Eleki (2017) in their study used a monthly Central African Franc (CFAFr or XAF) and Nigerian Naira (NGN) exchange rates from January 2004 to January 2017, and their results revealed that June 2016 is identified as the intervention period. This is the time Nigeria fall into a recession. The pre-intervention period proved to be nonstationary and becomes stationary after the first differencing. If a time series can be dominated by an intervention over a certain period, two distinct components in the model exist which are the deterministic part and the response. According to Tiwari et al. (2014), modelling strategy is to develop a sound exemplifications for both modules and iterate of the mode adequacy that is centred around the intermediate estimation, model diagnostics and interpretation. The overall series effects affect the model for the response term hence it becomes difficult to identify the model (Tiwari, Ram and Srivastava, 2014). One strategy is to use either of the series to model depending which portion of the residual $\mathrm{N}_{t}$ is provided in the analysis. Alternatively, one can also model with the generalized series by comparing the distinct periods. A composite choice of model can then be obtained during the process of checking for adequacy of the model based on possible changes made, external effects and on the series residual Etuk and Eleki (2017).

\section{Methodology}

Box et al. (2011) invented two models which are proposed for the current study. These models are known as SARIMA intervention and SARIMA respectively. Additionally, SARIMA model in this study serves as a 
benchmark model with which Makatjane and Moroke (2016) revealed that the multiplicative SARIMA model denoted by SARIMA $(p, d, q) \times(P, D, Q)_{S}$ follows this mathematical form:

$$
\Phi(\mathrm{L}) \Phi_{\mathrm{S}}\left(\mathrm{L}^{\mathrm{S}}\right)(1-\mathrm{L})^{\mathrm{S}}\left((1-\mathrm{L})^{\mathrm{D}} \mathrm{X}_{\mathrm{t}}=\Theta(\mathrm{L}) \Theta_{\mathrm{S}}\left(\mathrm{L}^{\mathrm{S}}\right) \varepsilon_{\mathrm{t}}\right.
$$

Where $\varepsilon_{t} \sim$ i. i. $d\left(\mu, \sigma_{t}^{2}\right)$ and $S$ is the seasonal length while $L$ is the lag operator. Tsay (2014), emphasized that there should be no common factors between the polynomials of seasonal autoregressive (SAR) and seasonal moving average (SMA); if not the order of the model must be in a reduced form. Moreover, SAR polynomials should acquaint with the characteristic equation of SARMA because that is the duty of SAR model Moroke (2015).

A SARMA model with weak stationarity is satisfied only if the absolute values of the solutions for the characteristic equation are less than one as it was discovered by Moroke (2014) and Tsay (2014). Ensuing Box et al. (2011), the general intervention model as emphasized by Montgomery et al. (2015) is presented by:

$$
\left.\mathrm{X}_{\mathrm{t}}=(\omega)(\mathrm{L}) \mathrm{L}^{\mathrm{b}} / \delta(\mathrm{L})\right) \mathrm{Z}_{\mathrm{t}}+\mathrm{N}_{\mathrm{t}}
$$

$\mathrm{Z}_{\mathrm{t}}$ is the intervention variable that occurred at time $\mathrm{T}$ and it is demarcated in equation (1.3)

$$
\mathrm{Z}_{\mathrm{t}}= \begin{cases}1, & \text { if } \mathrm{t} \geq \mathrm{T} \\ 0, & \text { if } \mathrm{t}<\mathrm{T}\end{cases}
$$

Therefore, $\omega$ is the unknown permanent change in the mean due to the intervention while $\delta$ is the unknown intervention parameter. Along with Lai and Lu (2005), the first term in (1.2) epitomizes the consequence of the intervention event in terms of the deterministic input series $Z_{t}$ and $N_{t}$ is the noise series which represents the background of observed time series $X_{t}$ without the intervention effect (Montgomery et al., 2015). Nonetheless, the assumption here is that $N_{t} \sim \operatorname{SARIMA}(p, d, q)$ or $\mathrm{N}_{\mathrm{t}} \sim \operatorname{SARIMA}(\mathrm{p}, \mathrm{d}, \mathrm{q})(\mathrm{P}, \mathrm{Q}, \mathrm{D})_{\mathrm{S}}$ models respectively. For further reading on intervention models, see also Oduro-Gyimah et al. (2012) and Otu et al. (2014). Because the 2008 financial crisis is unique, the intervention variable $Z_{t}$ symbolized some discrete event in which $Z_{t}=1$ denotes international financial crisis while $\mathrm{Z}_{\mathrm{t}}=0$ is otherwise. This is also evident by Montgomery et al. (2015).

Development of the model: In this section of the study we present the general development of the SARIMA model which is made up of the following three stages:

a) Unit root test and identification of the order of difference, i.e. $d$. pre-differencing a time series helps in reducing the variance of the data and makes the series ready to be modelled by a stationary S(ARIMA) model. Usually, Augmented Dickey-Fuller (ADF) is applied for the unit root test. The hypothesis tested is:

$\mathrm{H}_{0}: \rho=0$

$\mathrm{H}_{1}: \rho<0$ also see Mushtaq (2011) and Moroke (2014) respectively. Makatjane and Moroke (2016) have accentuated that the ADF test which was derived by Dickey and Fuller (1979) is used for linear time series models and the test follows some sort of linear regression as:

ADF equation with no intercept and no trend: $\Delta \mathrm{X}_{\mathrm{t}}=\rho \mathrm{X}_{\mathrm{t}-1}+\sum_{\mathrm{i}=1}^{\mathrm{p}} \delta_{\mathrm{i}} \Delta \mathrm{X}_{\mathrm{t}-\mathrm{i}}+\epsilon_{\mathrm{t}}$

ADF equation with intercept: $\Delta \mathrm{X}_{\mathrm{t}}=\beta_{0}+\rho \mathrm{X}_{\mathrm{t}-1}+\sum_{\mathrm{i}=1}^{\mathrm{p}} \delta_{\mathrm{i}} \Delta \mathrm{X}_{\mathrm{t}-\mathrm{i}}+\epsilon_{\mathrm{t}}$

ADF equation with intercept plus trend: $\mathrm{X}_{\mathrm{t}}=\beta_{0}+\beta_{1} \mathrm{t}+\rho \mathrm{X}_{\mathrm{t}-1}+\sum_{\mathrm{i}=1}^{\mathrm{p}} \delta_{\mathrm{i}} \Delta \mathrm{X}_{\mathrm{t}-\mathrm{i}}+\epsilon_{\mathrm{t}}$.

$\Delta$ is differencing operator, $\mathrm{t}$ is time drift; $\rho$ designates the selected maximum lag based on the minimum information criteria such as Akaike's information criteria (AIC), Schwartz Bayesian criteria (SBC) or HannanQuin criterial (HQC) values and $\varepsilon_{\mathrm{t}}$ is the error term despite the fact that $\beta$ and $\delta$ are the bounds of the model. Contingent on the results, the intercept, and intercept plus trend may be included in the model. The ADF test is computed by:

$$
\tau=\frac{\widehat{\gamma}}{\operatorname{se}(\widehat{\gamma)}} \sim t_{\alpha, n-p}
$$

Where the ADF test statistic is $\tau$ and $\hat{\gamma}$ is the process root coefficient. If the observed $|\tau|$ is greater than the critical value, no simple differencing is required since the series has been rendered stationary. For model selection, the AIC and SBC are employed in this study. With this regard, the SBC measure is estimated as follows:

$$
\mathrm{SBC}=-2[\ln \widehat{\varphi}+\mathrm{k} * \ln (\mathrm{n})] \text {, }
$$

where $\mathrm{n}$ is the sample size, $\mathrm{k}$ is the number of parameters to be estimated, $\widehat{\varphi}$ is the likelihood function of the estimated model (M) which is $\widehat{\varphi}=\mathrm{p}(\mathrm{x} \mid \hat{\theta}, \mathrm{M}), x$ is the observed data and $\theta$ is the parameter of the estimated ADF model. 
The study further uses the AIC for lag length selection of the ADF model. According to Pan (2001), AIC is most powerful widely used by most researchers:

$$
\mathrm{AIC}=\operatorname{nlog}\left(\frac{\mathrm{RSS}}{\mathrm{n}}\right)+2 \mathrm{k}
$$

In this case, $\mathrm{n}$ is the sample size, RSS residual sum of squares from the fitted ADF model while $2 \mathrm{k}$ is the variance of the same model, hence, the model with least AIC is the one selected to be the best model.

The Hanan Quin (HQ) is asymptotically efficient in estimating the best model because it produces fine turning criterion results which in practice it has the term $\log \log (n)$ which process small values even if the sample size $\mathrm{n}$ is very large (Hjort, 2008). Then the procedure is as follows:

$$
\mathrm{HQ}=-2 \log \tilde{L}_{n}\left(\theta_{n}\right)+2 \mathrm{ck}_{0} \log \log n, \mathrm{c}>1 \text {, }
$$

Where $\mathrm{k}_{0}$ a number of estimated parameters of the model is, $n$ is the sample size and $\tilde{L}_{n}\left(\theta_{n}\right)$ is the likelihood function.

b) Estimation and determination of the parameters of the intervention function and SARIMA, i.e. p and q. and or P and Q. According to Box et al. (2011), the autocorrelation function (ACF), partial autocorrelation function (PACF) and cross-autocorrelation function (CACF) are dynamic to tentatively identify the parameters of the model. Nonetheless, statistical measures generally give an outstanding proof to provision the determination of an appropriate intervention function. Furthermore, the theoretical characteristics of the ACF and PACF for a stationary SARMA process are presented in table 1. In order to attain robust results, the ACF and PACF patterns must cup tie with this theoretical patterns (Montgomery et al., 2015).

Table 1: Behavior of Theoretical ACF and PACF for stationary SARMA process

\begin{tabular}{cccc}
\hline & SARMA $(\mathbf{P}, \mathbf{0})_{\mathbf{s}}$ & SARMA $(\mathbf{0}, \mathbf{Q})_{\mathbf{s}}$ & SARMA $(\mathbf{P}, \mathbf{Q})_{\mathbf{s}}$ \\
\hline ACF & Tails off at lags ks & Cuts off after lag Qs & Tails off at lags k \\
PACF & Cuts after lag Ps & Tails off at lag ks & Tails off at lag k \\
\hline
\end{tabular}

Source: Montgomery et al. (2015)

Therefore, Jonathan and Kung-Sik (2008) have shown that the ACF can be derived from:

$$
\rho_{\mathrm{k}}=\frac{\rho_{\mathrm{k}}}{\rho_{0}}=\frac{\operatorname{cov}\left(\mathrm{X}_{\mathrm{t}}, \mathrm{X}_{\mathrm{t}-\mathrm{k}}\right)}{\operatorname{Var}\left(\mathrm{X}_{\mathrm{t}}\right)}, \mathrm{k}=0,1,2,3, \ldots
$$

Where, $\rho_{0}$ is the autocovariance which is computed as $\operatorname{cov}\left(\mathrm{X}_{\mathrm{t}}, \mathrm{X}_{\mathrm{t}-\mathrm{k}}\right)=\mathrm{E}\left(\mathrm{X}_{\mathrm{t}}^{2}\right)-\left(\mathrm{E}\left(\mathrm{X}_{\mathrm{t}}\right)\right)^{2}=\operatorname{Var}\left(\mathrm{X}_{\mathrm{t}}\right)$. Normally, a correlogram is used and it is a graph of $\rho_{\mathrm{k}}$ against $\mathrm{k}$. The PACF is computed as:

$$
\mathrm{a}_{\mathrm{kk}}=\left\{\begin{array}{cc}
\rho_{1} & , \mathrm{k}=1 \\
\frac{\rho_{\mathrm{k}}-\sum_{\mathrm{j}=1}^{\mathrm{k}-1} \mathrm{a}_{\mathrm{k}-1, \mathrm{j}} \rho_{\mathrm{k}-\mathrm{j}}}{1-\sum_{\mathrm{j}=1}^{\mathrm{k}} \mathrm{a}_{\mathrm{k}-1, \mathrm{j}} \rho_{\mathrm{j}}} & , \mathrm{k}=2,3,4, \ldots, \rho \\
0 & , \mathrm{k}>\rho
\end{array}\right.
$$

c) Residual or noise diagnostic check. The correlogram of Q-statistics based on the ACF and PACF of the residual is generally used for residual analysis and further the statistical tests such as the Jarque-Bera test for the normality of residuals, the Lagrange multiplier for the heteroscedasticity of the residuals and finally, BreuschGodfrey test is also used to test the correlation of the residuals.

\section{Empirical Analysis}

To execute the analysis, the study used a time series data of real exchange rate for the period of January 2000 to June 2017 which is accessed from the South African Reserve Bank database. The considered 2008 financial crisis is hypothesized to be a significant event in influencing exchange rate movements in SA. For the statistical analysis, R 3.4.3 programming is utilized. Nevertheless, figure1 parades the properties of the time series from the specified period. By visual examination, the series shows some upward and downward trends in conjunction with seasonal components. This implies that the real exchange rate in South Africa is not constant over the sampled period. The formal statistical test for the presence of seasonal components is reported in table 2. 


\section{Figure 1: Real exchange rate}

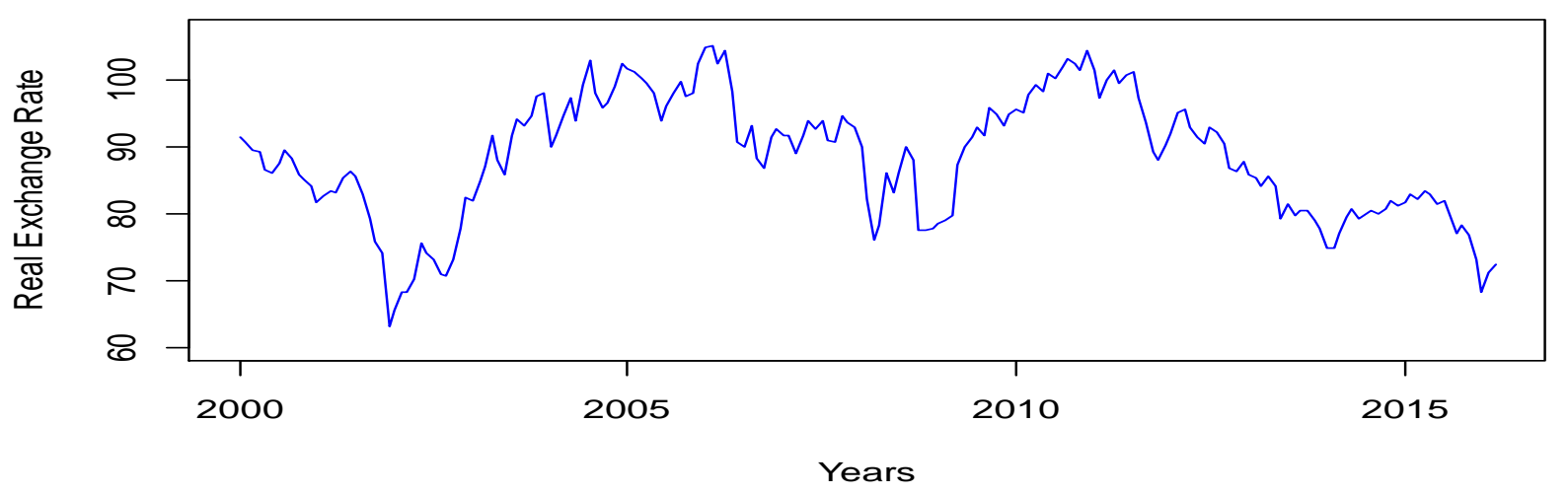

Table 2: Nonparametric Test for the Presence of Seasonality

\begin{tabular}{ccc}
\hline Kruskal-Wallis Statistic & DF & Sig \\
\hline 38.19472 & 11 & $* * *$ \\
\hline
\end{tabular}

Sign. Codes: ${ }^{* * *} 0.001 * * 0.01 * 0.05$

Revealed in table 2 is the Kruskal-Wallis (KW) statistic test for the presence of seasonal components. As observed in table 2, there is a huge significant evidence that the exchange rate holds the seasonal properties as the KW test rejects the null hypothesis of no seasonal components over the alternative if there are seasonal components in the exchange rate series. Hence we proceed with the proposed SARIMA and SARIMA intervention models.

Results and Analysis of SARIMA Model: The ADF test is applied to the time series as the purpose to accommodate both the Box-Jenkins and intervention proposed in this study. The results of the ADF test provided a sufficient evidence that the exchange rate series contains unit root with both seasonal and nonseasonal differencing of order one. i.e. $d=1$. The ADF model with three features discussed in section two is the one to be used as its $\operatorname{Pr}(\tau)=0.01$. Therefore, a stationary time series is achieved. In model selection, the ACF, PACF, SBC and AIC congruently advocate that the SARIMA model is of the form of $\operatorname{ARIMA}(2,1,0)(2,1,0)_{12}$ in which the model is formulated below.

$$
\mathrm{X}_{\mathrm{t}}=[1-0.22 \Phi * * *(1)(1+0.15 \Phi * * *(2))(1+0.61 \Phi * * *(12)(1+0.38 \Phi * * * 13))] \varepsilon_{\mathrm{t}}
$$

While diagnosing the estimatedARIMA $(2,1,0)(2,1,0)_{12}$, all the estimated parameters are significant at $1 \%, 5 \%$ and $10 \%$ level of significance. Additionally, the estimated Q-statistics also gave a vast significant evidence that the estimated model is a white noise process with $\operatorname{Pr}\left(Q_{\text {statistic }}=0.1732\right)$ and $\varepsilon_{t} \sim$ i. i. $d(0,0.02978)$. Yaffee and McGee (2000) have suggested that model parameter estimates must be less than one as to deem them to be sufficient and significant. The same results are also obtained by Makatjane and Moroke (2016) in their study of comparative of Holt-Winters triple exponential smoothing and Seasonal ARIMA models.

SARIMA-Intervention Results: The intervention model is explored with the 2008 financial crisis being the intervention period. Due to the reason that in March 2008 this financial crisis protracted to $S A$, then $Z_{t}$ is initiated during this period. Before estimation of an intervention model, ADF test with the pre-mentioned three features is applied and delivers much evidence that pre-intervention time series has no unit root as the $\operatorname{Pr}(\tau)=$ 0.032 which is less than the observed probability of $5 \%$ when the order of integration is zero i.e. $d=0$. The intervention model is estimated by firstly identifying the order of intervention parameters by utilizing the ACF and PACF and further selects the best model by SBC and AIC. And finally, the diagnostic checks that are executed for the noise proves that it is a white noise process and hence the estimated model is valid.

$\mathrm{Y}_{\mathrm{t}}=\frac{(1-0.033)}{(1+0.743)} \mathrm{Z}_{\mathrm{t}}+[(1-0.403 \theta * * *(1))(1+0.999 \Theta * * *(12))] \varepsilon_{\mathrm{t}}, \varepsilon_{\mathrm{t}} \sim$ i. i. d $(0,0.00404)$. 


\begin{tabular}{l} 
Journal of Economics and Behavioral Studies (ISSN: 2220-6140) \\
Vol. 10, No. 1, pp. 59-68, February 2018 \\
\hline \hline
\end{tabular}

The cross-autocorrelation function (CACF) shows a significant spike in lag $0 \hat{\rho}_{0}=0.998$ and a decay pattern after lag 1 indicating that the2008 financial crisis did directly distress the SA exchange rate which brought a significant drop in import and exports of goods and services in SA the month after the event. The intervention effect is computed as an asymptotic change of $17 \%$. This implies that the effect of the intervention had caused a drop of $17 \%$ in exchange rate hence the same decline in the SA economy.

Table 3: SARIMA and SARIMA Intervention model estimates

\begin{tabular}{cccc}
\hline \multicolumn{4}{c}{ SARIMA model } \\
\hline Parameter & Estimate & Standard Error & Z value \\
$\phi_{1}$ & 0.21814 & 0.07328 & $2.9769^{* * *}$ \\
$\phi_{2}$ & -0.14772 & 0.07358 & $-2.0077^{* * *}$ \\
$\Phi_{1}$ & -0.60886 & 0.06961 & $-8.7463^{* * *}$ \\
$\Phi_{2}$ & -0.37643 & 0.07246 & $-5.1951^{* * *}$ \\
SC & -94.74 & AIC & -110.76 \\
\hline \multicolumn{4}{c}{ SARIMA Intervention model } \\
\hline Parameter & Estimate & Standard Error & Z value \\
$\theta_{1}$ & 0.403 & 0.078 & $5.190^{* *}$ \\
$\Theta_{1}$ & -1.000 & 0.073 & $-13.76^{* * *}$ \\
March08-AR1 & -0.743 & 0.076 & $-9.810^{*}$ \\
March08-MA0 & -0.033 & 0.009 & $-3.610^{* * *}$ \\
SC & -426.923 & AIC & -445.288 \\
\hline
\end{tabular}

Sign. Codes: ${ }^{* * *} 0.001{ }^{* *} 0.01 * 0.05$

Comparative analysis: The purpose of this section is to determine the model which best mimics the data and produces fewer forecasts. With the extension to Makatjane and Moroke (2016) methodology, the current study follows up with the application of four error metrics which are a mean error, mean absolute error, mean percentage error and mean absolute percentage error to measure the performance of each model and results are summarized in Table 3. The results indicate that the model with intervention has the smallest values of all the proposed error metrics. Hence the conclusion that this model dominates the counterpart SARIMA model. The same conclusion is made based on the values of SBC and AIC reported in table 3 where SARIMA model with the intervention has the smallest of both the SBC and AIC as compared to the model without the intervention suggesting that the model with intervention is the best model. According to Lai and Lu (2005), the SARIMA produces a delay forecast regarding the sudden occurrences of the intervention in the data.

Table 4: Performance model selection Criteria

\begin{tabular}{ccc}
\hline Performance Criteria & SARIMA & SARIMA Intervention \\
\hline ME & 0.0023 & 0.0011 \\
MAE & 0.1247 & 0.0451 \\
MPE & 0.0222 & 0.0106 \\
MAPE & 1.3377 & 0.5052 \\
\hline
\end{tabular}




\section{Figure 2: Actual VS Conditional Mean}

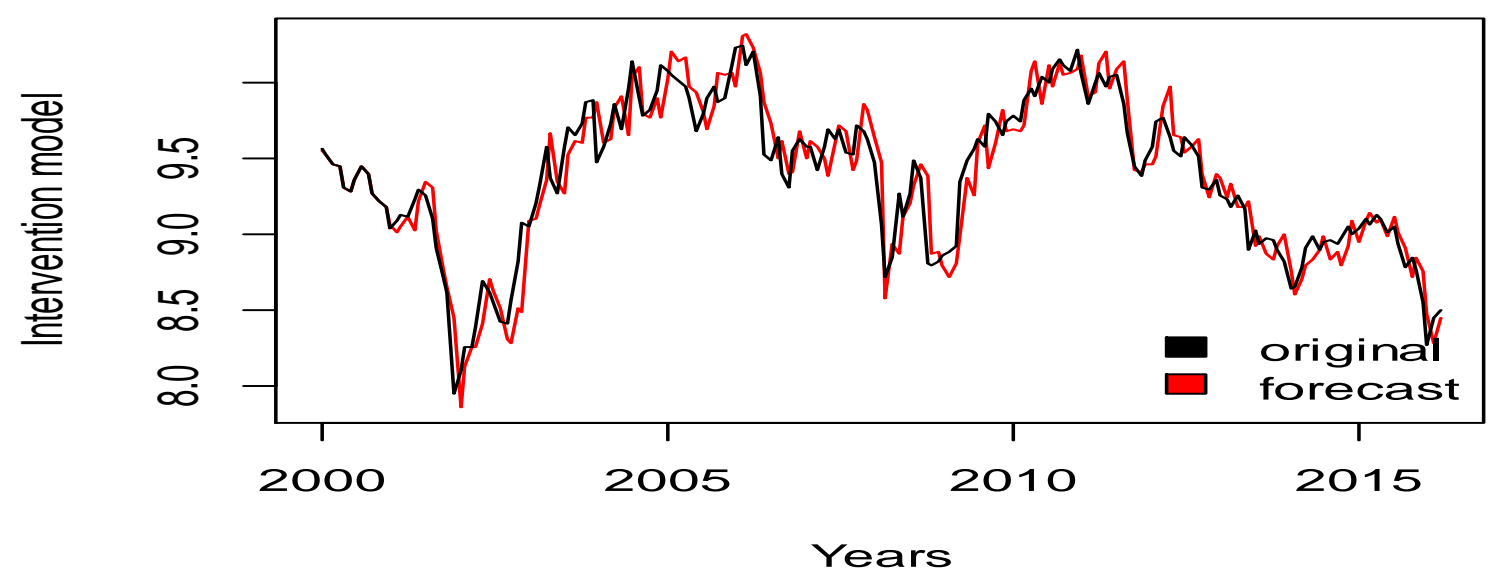

Figure 2 presents the fitted conditional mean for the SARIMA intervention model. By eye inspection, the model seems to fit the exchange rate data well. This suggests that the SARIMA intervention model has performed relatively well in tracking the exchange rate movement for the specified intervention period.

\section{Conclusion and Recommendations}

The U.S. financial crisis was triggered in July 2007; however, it did not affect SA's economy until later, when it became a disaster and turned into a global economic problem. The intervention effect of the global financial crisis that began in March 2008 in SA, as measured in this study, is immediate and alarming. This significant negative effect has led to a dramatic decline in SA output value since March 2008, which is likely to have continued throughout 2008 and 2009 before reaching a steady state. Moroke et al. (2014) reported that during this period, resources were downgraded, companies were shut down causing unemployment rates to accelerate with the overall diminishing of the country's economic growth. For the comparative results, the study has found that the SARIMA model with intervention out-performed the SARIMA model and the application of SARIMA intervention models is appropriate for explaining the dynamics and impact of interruptions and changes of time-series in a more detailed and precise manner. This study provides practical information for the monetary policy committee of SA to make informed policy decisions related to exchange rates. It further gives sound relevance in using the intervention model to model interrupted time series such as exchange rates. To other scholars, the study had shown that a seasonal time series that is interrupted by policies in a financial crisis can be modelled by the SARIMA intervention model. However, other scholars should also extend this empirical analysis to the multivariate modelling by using the determinants of the exchange rate and utilize the SARIMAX model with intervention to give more understanding on the linear relationship and co-movement of the exchange rate in South Africa.

\section{References}

Box, G.E., Jenkins, G.M. \& Reinsel, G.C. 2011. Time series analysis: forecasting and control. Vol. 734: John Wiley $\&$ Sons.

Chung, R.C., Ip, W. \& Chan, S. 2009. An ARIMA-intervention analysis model for the financial crisis in China's manufacturing industry. International Journal of Engineering Business Management, 1:5.

Coshall, J.T. 2003. The threat of terrorism as an intervention on international travel flows. Journal of Travel Research, 42 (1):4-12.

Dickey, D.A. \& Fuller, W.A. 1979. Distribution of the estimators for autoregressive time series with a unit root. Journal of the American Statistical Association, 74 (366a):427-431. 
Ebhuoma, O., Gebreslasie, M. \& Magubane, L. 2017. Modeling malaria control intervention effect in KwaZuluNatal, South Africa using intervention time series analysis. Journal of Infection and Public Health, 10 (3):334-338.

Eisendrath, D., Bernhard, B.J., Lucas, A.F. \& Murphy, D.J. 2008. Fear and managing in Las Vegas: An analysis of the effects of September 11, 2001, on Las Vegas Strip gaming volume. Cornell Hospitality Quarterly, 49 (2):145-162.

Etuk, E.H. \& Eleki, A.G. 2017. Arima Intervention Analysis of Monthly Xaf-Ngn Exchange Rates Occasioned By Nigerian Economic Recession.

Hjort, N.L. 2008. Model selection and model averaging. Cambridge Series in Statistical and Probabilistic Mathematics. Cambridge University Press.

Jonathan, D. \& Kung-Sik, C. 2008. Time Series Analysis With Applications in R. New York: Springer Science and Business Media, LLC.

Lai, S.L. \& Lu, W.-L. 2005. Impact analysis of September 11 on air travel demand in the USA. Journal of Air Transport Management, 11 (6):455-458.

Lippi, M, Bertini, M. \& Frasconi, P. 2013. Short-term traffic flow forecasting: An experimental comparison of time-series analysis and supervised learning. IEEE Transactions on Intelligent Transportation Systems, $14(2): 871-882$.

Makatjane, K.D. \& Moroke, N.D. 2016. Comparative Study of Holt-Winters Triple Exponential Smoothing and Seasonal Arima: Forecasting Short-Term Seasonal Car Sales in South Africa. Risk Governance \& Control: Financial Markets \& Institutions, 6 (1).

Mayosi, B.M, Lawn, J.E, Van Niekerk, A, Bradshaw, D, Karim, S.S.A, \& Coovadia, H.M. 2012. Health in South Africa: changes and challenges since 2009. The Lancet, 380 (9858):2029-2043.

Min, J.C, Lim, C. \& Kung, H.-H. 2011. Intervention analysis of SARS on Japanese tourism demand for Taiwan. Quality \& Quantity, 45 (1):91-102.

Montgomery, D.C, Jennings, C.L. \& Kulahci, M. 2015. Introduction to time series analysis and forecasting. John Wiley \& Sons.

Moroke, N.D. 2014. The robustness and accuracy of Box-Jenkins ARIMA in modelling and forecasting household debt in South Africa. Journal of Economics and Behavioral Studies, 6 (9):748.

Moroke, N.D. 2015. Box-Jenkins transfer function framework applied to the saving-investment nexus in the South African context.

Moroke, N.D, Mukuddem-Petersen, J. \& Petersen, M. 2014. A Multivariate Time Series Analysis of Household Debts during 2007-2009 Financial Crisis in South Africa: A Vector Error Correction Approach. Mediterranean Journal of Social Sciences, 5 (7):107.

Mushtaq, R. 2011. Augmented Dickey-Fuller Test.

Naudé, W. 2009. The financial crisis of 2008 and the developing countries. UNU-WIDER Discussion Paper No. 2009/01.

Oduro-Gyimah, F, Harris, E. \& Darkwah, K. 2012. Sarima time series model application to microwave transmission of Yeji-Salaga (Ghana) line-of-sight link. International Journal of Applied, 2 (9).

Orlowski, L.T. 2008. Stages of the 2007/2008 Global Financial Crisis Is There a Wandering Asset-Price Bubble?

Otu, O.A, Jude, O. \& Ifeyinwa, M.H. 2014. Application of Sarima Models in modelling and forecasting Nigeria's Inflation rates. American Journal of Applied Mathematics and Statistics, 2 (1):16-28.

Pan, W. 2001. Akaike's information criterion in generalized estimating equations. Biometrics, 57 (1):120-125.

Park, M.S, Eom, J.K, Heo, T.-Y. \& Song, J. 2016. Intervention analysis of the impact of opening a new railway line on passenger ridership in Seoul. KSCE Journal of Civil Engineering, 20 (6):2524-2534.

Tiwari, R, Ram, D. \& Srivastava, M. 2014. Temperament and character profile in obsessive-compulsive disorder (OCD): A pre and post-intervention analysis. International Journal of School and Cognitive Psychology, $1(2): 1-9$.

Tsay, R.S. 2014. An introduction to the analysis of financial data with R. John Wiley \& Sons.

Xie, Y, Zhao, K, Sun, Y. \& Chen, D. 2010. Gaussian processes for short-term traffic volume forecasting. Transportation Research Record: Journal of the Transportation Research Board, (2165):69-78.

Yaffee, R. \& McGee, M. 2000. Introduction to Time Series Analysis and Forecasting with Applications of SAS and SPSS. San Diego. Cal: Academic Press.

Ye, Q, Szeto, W.Y. \& Wong, S.C. 2012. Short-term traffic speed forecasting based on data recorded at irregular intervals. IEEE Transactions on Intelligent Transportation Systems, 13 (4):1727-1737. 


\section{Journal of Economics and Behavioral Studies (ISSN: 2220-6140)}

Vol. 10, No. 1, pp. 59-68, February 2018

Zhang, N, Zhang, Y. \& Lu, H. 2011. Seasonal autoregressive integrated moving average and support vector machine models: Prediction of short-term traffic flow on freeways. Transportation Research Record: Journal of the Transportation Research Board, (2215):85-92.

Zheng, T. 2014. What caused the decrease in RevPAR during the recession? An ARIMA with intervention analysis of room supply and market demand. International Journal of Contemporary Hospitality Management, 26 (8):1225-1242.

Zheng, T, Farrish, J. \& Wang, X. 2013. How did different restaurant segments perform differently through the recession? An ARIMA with intervention analysis on US restaurant stock indices. Journal of Hospitality Financial Management, 20 (2):1.

\section{Appendix}

First Seasonal Augmented Dickey-Fuller Test

\begin{tabular}{llll}
\hline Type & Lag Order & Dickey-Fuller & P Value \\
\hline no intercept and no trend & 2 & -7.4594 & 0.01 \\
Intercept & 2 & -7.4391 & 0.01 \\
Intercept plus Trend & 2 & -7.4156 & 0.01 \\
\hline
\end{tabular}

\section{First Seasonal differencing ACF and PACF plots}
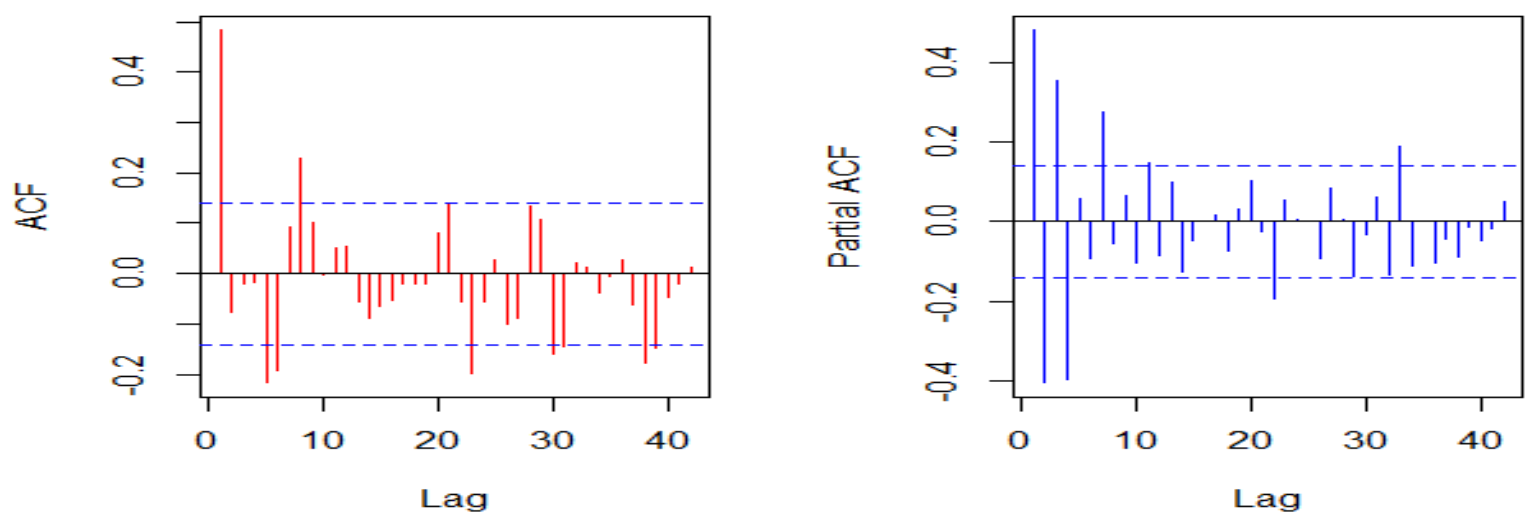

\section{Intervention Period}

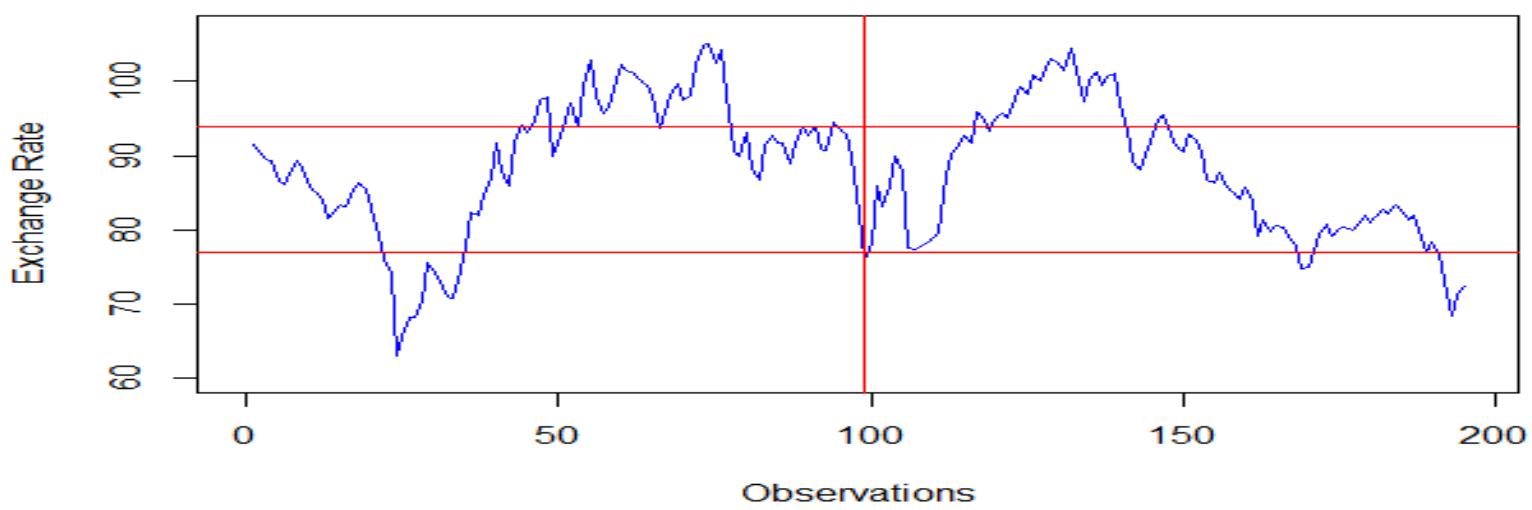




\section{Pre-intervention ADF test}

\begin{tabular}{llll}
\hline Type & Lag Order & Dickey-Fuller & P Value \\
\hline no intercept and no trend & 2 & -3.7368 & 0.032 \\
Intercept & 2 & -3.7141 & 0.032 \\
Intercept plus Trend & 2 & -3.717 & 0.032 \\
\hline
\end{tabular}

Pre-intervention ACF and PACF plots
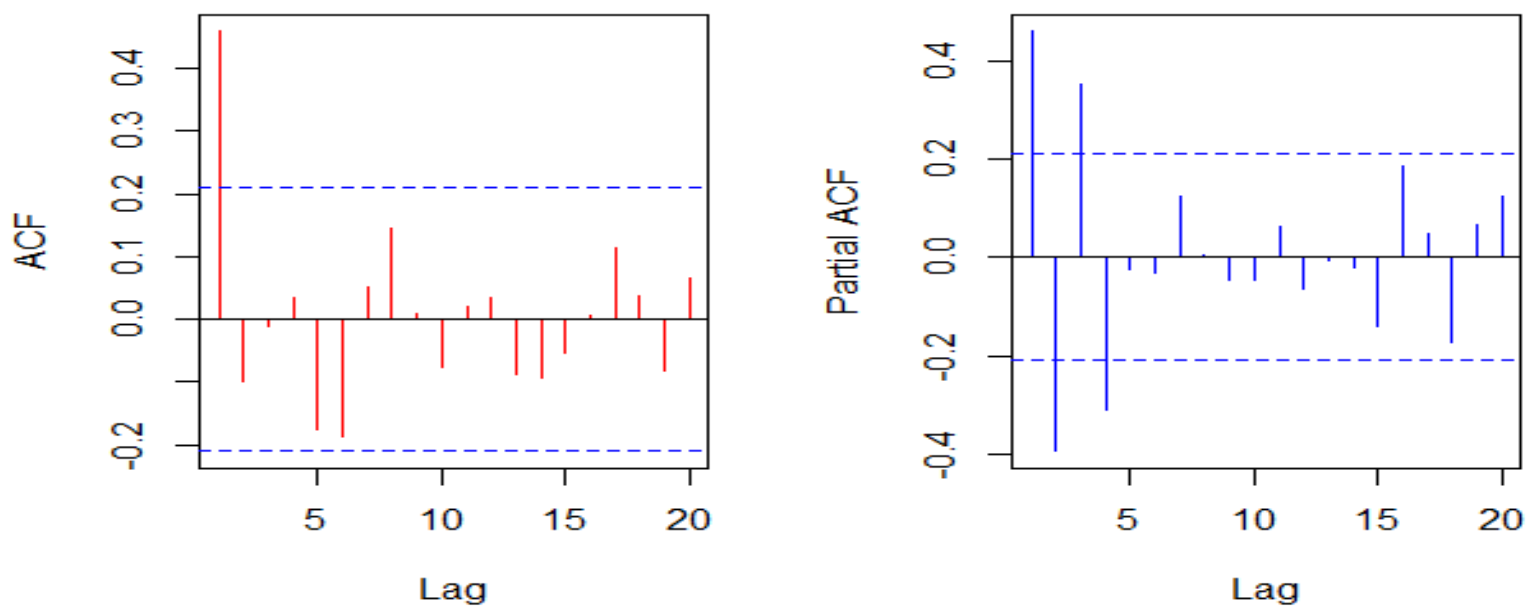

Computation of Intervention Effect

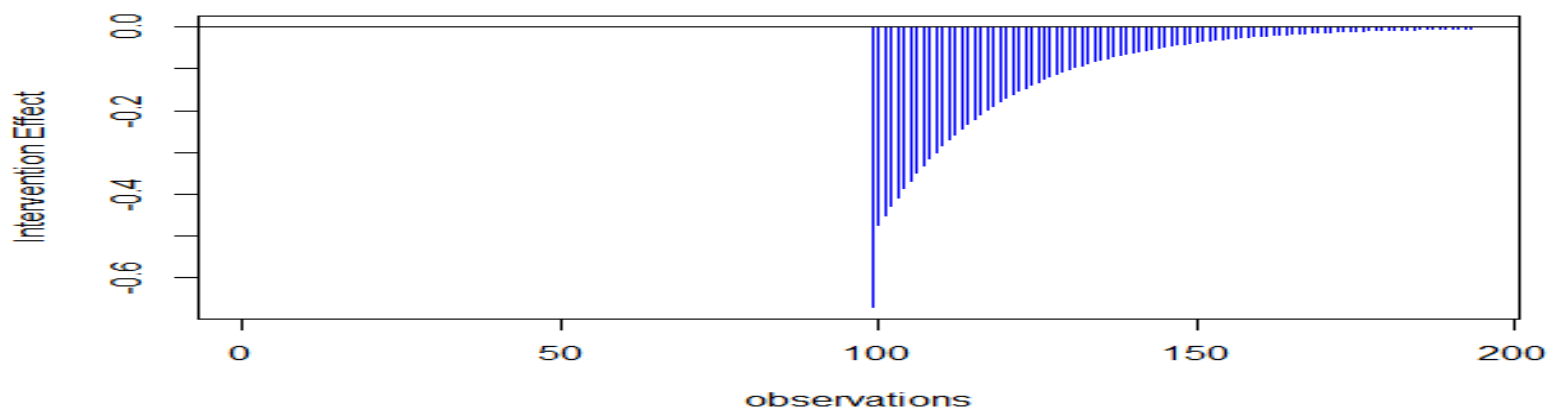

